TP Periodica Polytechnica Chemical Engineering

\author{
59(2), pp. 111-123, 2015 \\ DOI: $10.3311 /$ PPch.7665
}

Creative Commons Attribution (i)

RESEARCH ARTICLE

\section{Pervaporation of Ethanol/Water Mixtures Through a High-Silica MFI Membrane: Comparison of Different Semi-Empirical Mass Transfer Models}

\author{
Tiina Leppäjärvi ${ }^{1,}$, Ilkka Malinen ${ }^{1}$, Danil Korelskiy ${ }^{2}$, \\ Jani Kangas ${ }^{1}$, Jonas Hedlund ${ }^{2}$, Juha Tanskanen ${ }^{1}$ \\ Received 18 August 2014; accepted after revision 20 October 2014
}

\begin{abstract}
Pervaporation of binary ethanol/water solutions of 5-10 wt.\% ethanol was studied experimentally through a thin supported high-silica MFI zeolite membrane of hydrophobic character in the temperature range of $30-70{ }^{\circ} \mathrm{C}$. The fluxes obtained were very high, 2-14 $\mathrm{kg} \mathrm{m}^{-2} \mathrm{~h}^{-1}$ with ethanol/water separation factors of 4-7. The loss of effective driving force was significant in the supporting layers, which limited the membrane performance. The correlation between the experimental data and three different semi-empirical mass-transfer models was examined. The correlation was good especially when the driving force for mass-transfer was determined based solely on bulk feed, or the bulk feed and permeate conditions together. Somewhat lower correlation was observed when the driving force was corrected with the effect of support resistance. This was most likely due to the inaccuracies of the used mass transfer parameters in the support. The investigated semi-empirical models can be applied for initial stage process design purposes.
\end{abstract}

\section{Keywords}

pervaporation, modeling, zeolite membranes, MFI, ethanol/ water mixtures

\footnotetext{
${ }^{1}$ Chemical Process Engineering, Faculty of Technology, University of Oulu, P.O. Box 4300, FI-90014 Oulu, Finland

${ }^{2}$ Chemical Technology, Luleå University of Technology, SE-97187 Luleå, Sweden

*Corresponding author, e-mail: tiina.leppajarvi@oulu.fi
}

\section{Introduction}

As energy issues have become increasingly important, there has been a growing interest towards separation processes with low energy consumption, such as pervaporation. Pervaporation is potential, e.g. in biofuel production [1,2]. Selective removal of ethanol straight from the fermentation broths by integrating pervaporation into fermentation would increase the productivity of fermentors and decrease the separation costs.

Various membrane materials have been studied in the recovery of organic compounds from water-containing streams by pervaporation. Rubbery polymers have been recognized as potential materials for organophilic pervaporation applications, the most common being polydimethylsiloxane PDMS, often referred to as silicone rubber. PDMS membranes are also commercially available. The reported ethanol-water separation factors using PDMS membranes vary between 4 and 11 [2-4]. The reported total fluxes, however, are typically relatively low, mostly below $1 \mathrm{~kg} \mathrm{~m}^{-2} \mathrm{~h}^{-1}[3,5-8]$. The modification of PDMS membranes with fillers such as hydrophobic zeolites, referred to as mixed matrix membranes, has also been studied [9-11]. In many cases, the ethanol-water separation factor using such membranes has been increased, up to as high as 59, with the total flux remaining mostly below $1 \mathrm{~kg} \mathrm{~m}^{-2} \mathrm{~h}^{-1}$ [12].

Over the past decades, inorganic zeolite membranes have also received increasing interest in pervaporation. Zeolite membranes are claimed to offer some advantages over polymeric membranes: zeolite structures are chemically more stable than polymeric membranes, zeolites can tolerate quite high temperatures, and zeolite membranes do not swell $[13,14]$. The first large scale use of zeolite membranes was reported by Morigami et al. [15] using $\mathrm{NaA}$ membranes for solvent dehydration. For organic removal from water-containing streams, MFI membranes have been studied the most, especially silicalite- 1 membranes. The advantage of silicalite- 1 membranes in the separation of ethanol from aqueous solutions is attributed to the hydrophobic properties and well-defined pore size of silicalite crystals [16]. Ethanol-water separation factors of up to 106 [17] have been reported in pervaporation through MFI membranes, with the typical value being around 40 [2]. The typical value for total 
flux is around $1 \mathrm{~kg} \mathrm{~m}^{-2} \mathrm{~h}^{-1}$. However, a flux of as much as 4.02 $\mathrm{kg} \mathrm{m}^{-2} \mathrm{~h}^{-1}$ (at $60{ }^{\circ} \mathrm{C}$ ) on a tubular support has been reported [16]. Even a higher flux, $7.40 \mathrm{~kg} \mathrm{~m}^{-2} \mathrm{~h}^{-1}$ (at $60{ }^{\circ} \mathrm{C}$ ), has been reached using a hollow fiber MFI membrane [18].

The aim in zeolite membrane synthesis is to produce membranes that are as thin as possible in order to obtain high fluxes, and at the same time the membranes should have a low amount of defects to display high selectivities. In addition, the membrane preparation procedure should be reproducible and the membranes should be durable. Zeolite membranes are typically synthesized on porous inorganic supports, which are needed to supply the mechanical strength to the thin membranes. The MFI membranes prepared are typically tens of micrometers [16,17,19-21] or several hundreds of micrometers thick [22-24]. However, as thin as ca. $500 \mathrm{~nm}$ MFI membranes have also been prepared and evaluated for different separations for more than 10 years, by the research group headed by Professor Hedlund [25-29].

In order to be able to predict membrane performance and design membranes for specific applications, a fundamental understanding of transport phenomena is required. However, it is challenging to develop a mass transfer model for pervaporation applicable for all types of membrane materials and separated mixtures. The swelling behavior of polymeric membranes and the multi-feature diffusion mechanisms through inorganic membranes prohibit the development of a universal mass transfer model for pervaporation [30].

In addition, the exact transport and separation mechanisms are still yet not fully understood [31]. The sorption-diffusion model is the most accepted model to describe the pervaporation process through inorganic membranes. Figure 1 illustrates the steps that are often recognized to affect the mass transfer in pervaporation through a composite zeolite membrane.

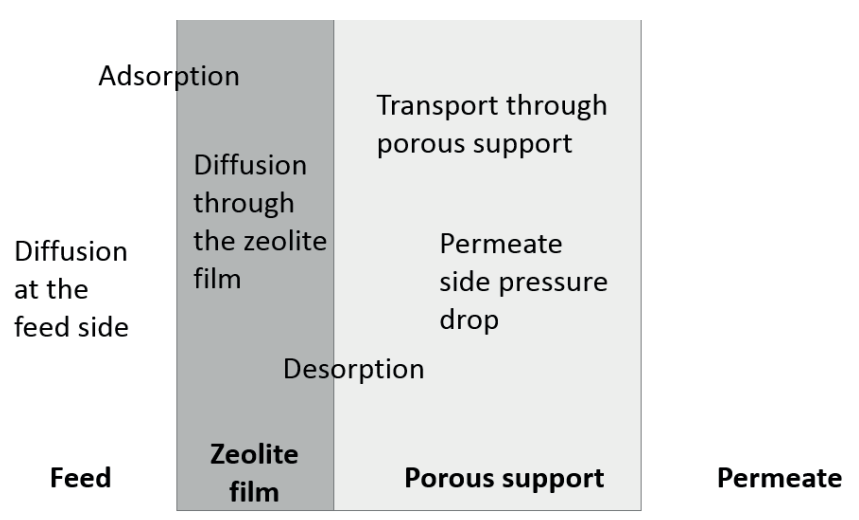

Fig. 1 Transport steps in pervaporation through zeolite membranes.

The adsorption and diffusion steps are typically considered to determine the mass transfer rates of the components and thus the selectivity of the membrane in pervaporation [32].

The models for mass transfer in pervaporation are mainly semi-empirical combining features of theoretical and empirical approaches [32]. Besides semi-empirical models [1,33], models also based on, for example, Maxwell-Stefan formulations [34-37] have been used in describing pervaporation separation using microporous membranes. In addition, molecular dynamics simulations have been applied [35,38-40]. Most of the modeling work in pervaporation through zeolite membranes is related to dehydration whereas modeling of separations of organic compounds from aqueous solutions is less common.

In this paper, pervaporation of binary ethanol/water mixtures of different compositions at various feed temperatures through a ca. $500 \mathrm{~nm}$ thick high-silica MFI membrane is studied. Semiempirical mass-transfer models of three levels are exploited. The model parameters are fitted on the basis of experimental data, and the correlation between experimental data and each model is compared.

\section{Theory}

\subsection{Temperature-dependency of flux in pervaporation}

In pervaporation, both the permeability of the membrane film and the driving force for mass transfer are influenced by temperature [41]. Typically, the permeation flux through the membrane increases exponentially with increasing temperature [33]. The temperature-dependency of fluxes in pervaporation is often described by an Arrhenius -type equation

$$
J_{i}=J_{0, i} \exp \left(-E_{i}^{a p p} / R T\right),
$$

where $J_{0, i}$ is the pre-exponential factor $\left(\mathrm{kg} \mathrm{m}^{-2} \mathrm{~h}^{-1}\right), R\left(\mathrm{~J} \mathrm{~mol}^{-1} \mathrm{~K}^{-1}\right)$ is the gas constant, and $T(\mathrm{~K})$ is the temperature. $E_{i}^{a p p}\left(\mathrm{~J} \mathrm{~mol}^{-1}\right)$ is the apparent activation energy for flux characterizing the overall temperature-dependency of transport in pervaporation, i.e. taking into account the effects of temperature on adsorption and diffusion in the membrane, as well as on the driving force represented by chemical potential gradient over the membrane.

\subsection{Modeling the mass transfer in pervaporation through a zeolite membrane}

As solution-diffusion model is the most widely accepted model to describe transport in pervaporation for polymeric membranes, semi-empirical pervaporation models mostly based on solution-diffusion have been derived, such as the models of Wijmans and Baker [42] and Rautenbach [43,44]. In semi-empirical models, experimental data are required to determine certain parameters for the models. As adsorptiondiffusion model for inorganic membranes is analogous to the solution-diffusion model for polymeric membranes, similar semi-empirical models can be applied to describe transport through inorganic membranes.

Wijmans and Baker [42] showed that the component flux in pervaporation through polymeric membranes can be described by multiplying the permeance with the driving force. The driving force in pervaporation, i.e. the chemical potential gradient over the membrane, can be described using the fugacity difference of the feed and permeate. Similar model has also been applied to describe the mass transfer through inorganic silica [45] and 
zeolite membranes [1,33]. In the models, the permeation flux of a component is expressed with the permeance $Q_{i}$, which includes effects of affinity (adsorption) and diffusivity of permeating species, multiplied by the fugacity difference of a component over the membrane as introduced in Eq. (2). The permeate can be assumed to be an ideal gas at the low pressures usually applied on the permeate side in pervaporation. Therefore, the component fugacity on the downstream side of the membrane can be expressed as partial pressure.

$$
J_{i}=Q_{i}\left(f_{i}^{f}-f_{i}^{p}\right)=Q_{i}\left(x_{i} \gamma_{i} P_{i}^{s a t}-y_{i} P_{\text {perm }}\right),
$$

where $f_{i}^{f}(\mathrm{~Pa})$ is the fugacity of component $i$ in feed, $f_{i}^{p}(\mathrm{~Pa})$ is the fugacity of component $i$ in permeate, $Q_{i}\left(\mathrm{~kg} \mathrm{~m}^{-2} \mathrm{~h}^{-1} \mathrm{~Pa}^{-1}\right)$ is the permeance of component $i, x_{i}$ and $y_{i}$ are the mole fractions of component $i$ in the feed and in the permeate, $\gamma_{i}$ is the activity coefficient of component $i$ in feed liquid mixture, $P_{i}^{\text {sat }}(\mathrm{Pa})$ is the saturated vapor pressure of component $i$, and $P_{\text {perm }}(\mathrm{Pa})$ is the permeate side total pressure.

The temperature-dependency of the permeance can be described as

$$
J_{i}=Q_{i}^{r e f} \exp \left[\frac{-E_{i}^{P}}{R}\left(\frac{1}{T}-\frac{1}{T_{r e f}}\right)\right],
$$

where $Q_{i}^{\text {ref }}\left(\mathrm{kg} \mathrm{m}^{-2} \mathrm{~h}^{-1} \mathrm{~Pa}^{-1}\right)$ is the permeance of component $i$ at a reference temperature $T_{\text {ref }}$, which is for example, the mean temperature of the experiments. $E_{i}^{P}\left(\mathrm{~J} \mathrm{~mol}^{-1}\right)$ is the activation energy of permeance for component $i$, which characterizes the temperature effect of adsorption and diffusion in the zeolite layer, thus including both the activation energy of diffusion and the enthalpy of adsorption [46]. It is convenient to describe the temperature-dependency of membrane permeation with $E_{i}^{p}$ since besides the contributions of adsorption and diffusion, the apparent activation energy $E_{i}^{a p p}$ or flux in Eq. (1) also contains the temperature-dependency of the driving force. In Eq. (2), the dependency of permeation rates on composition, pressure, and also temperature, is included in the fugacity difference as a driving force.

In this paper, models of three levels based on Eq. (2) are applied to describe the mass transfer in the pervaporation of ethanol/water solutions through a high-silica MFI membrane. The model parameters are fitted based on the experimental data, and the correlation is compared between the models of different levels.

\section{Model 1, omitting the permeate side pressure}

In some studies the permeate-side pressure, and thus fugacity, is omitted completely in the membrane model [47,48]. Ignoring the permeate-side fugacity in Eq. (2) is generally justified on the basis that the permeate side pressure is usually very low. Thus, in addition to temperature-dependency for permeance, Model 1 has only feed-side fugacity term illustrating the driving force as

$$
Q_{i}=Q_{i, 1}^{r e f} \exp \left[\frac{-E_{i, 1}^{P}}{R}\left(\frac{1}{T}-\frac{1}{T_{r e f}}\right)\right] \cdot\left(x_{i} \gamma_{i} P_{i}^{s a t}\right) .
$$

\section{Model 2, permeate fugacity from the experiments}

In Model 2, the permeate side fugacity is taken into account in describing the driving force across the membrane as

$$
J_{i}=Q_{i, 2}^{r f f} \exp \left[\frac{-E_{i, 2}^{p}}{R}\left(\frac{1}{T}-\frac{1}{T_{r f}}\right)\right] \cdot\left(x_{i} \gamma_{i} P_{i}^{\text {sat }}-y_{i} P_{p}\right)
$$

This kind of model has been applied to the description of pure component transport through microporous silica membranes [45], dehydration of alcohols with A-type zeolite membranes [33], and also for the removal of ethanol from aqueous streams by multi-channel MFI zeolite membranes [1].

\section{Model 3, support correction}

The membrane support may have a significant contribution to the total mass transfer resistance [21,26,49-51]. The role of the support should be taken into account since the mass transfer resistance over the support limits the fluxes by lowering the effective fugacity difference across the zeolite film. On the other hand, the application of the support correction is expected to yield enhanced knowledge of the behavior and properties of the membrane. In addition, the predictive capabilities of the model may be improved. Figure 2 shows a schematic representation of the fugacity change over the composite membrane used in this study.

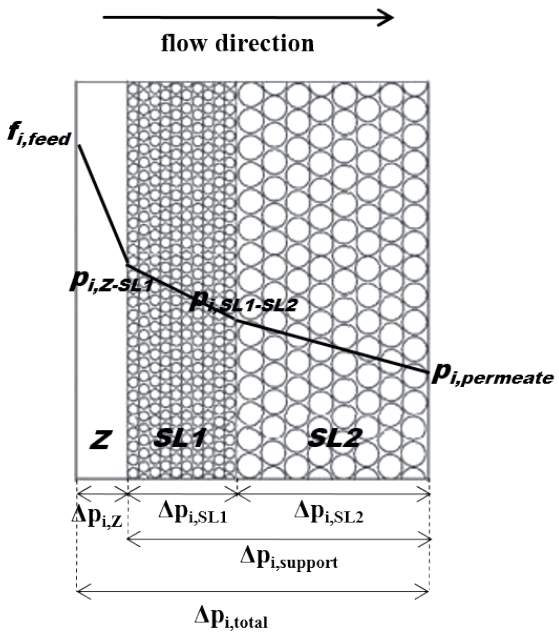

Fig. 2 Schematic representation of the composite zeolite membrane and the fugacity profile over the zeolite film $(Z)$ and support layers $1(S L 1)$ and $2(S L 2)$.

Even though the support layer can contribute to the overall mass transfer resistance, it is usually omitted in mass transfer models. In Model 3, however, the permeate-side fugacities are determined from a correction for the pressure difference over the support, whereas the feed-side fugacities are still determined from bulk properties 


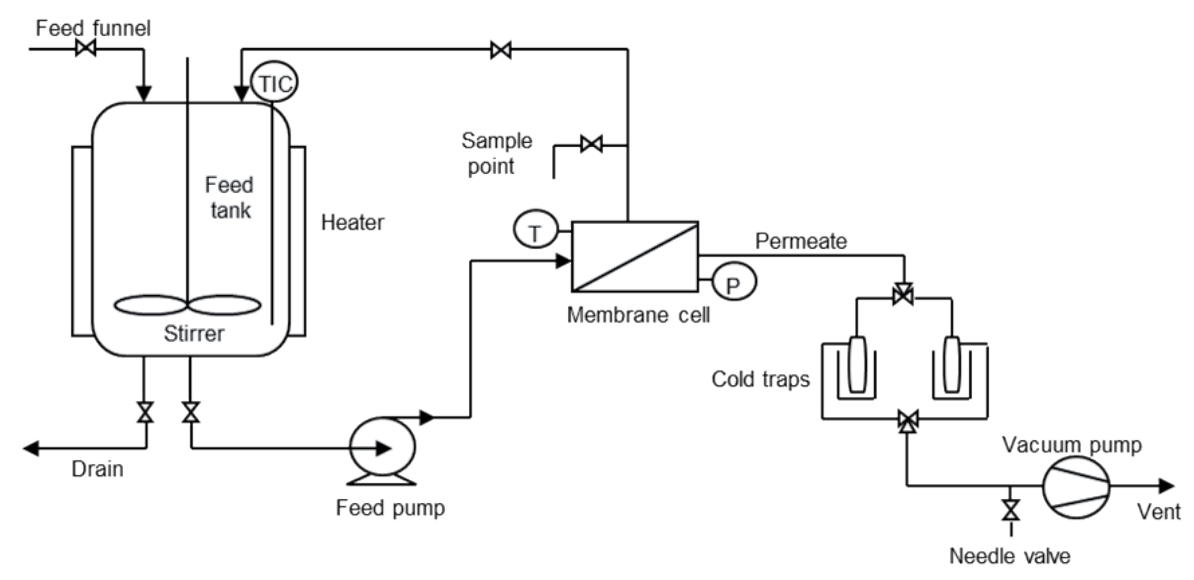

Fig. 3 Schematic representation of the setup for the pervaporation equipment.

$$
\begin{gathered}
J_{i}=Q_{i, 3}^{r e f} \exp \left[\frac{-E_{i, 3}^{p}}{R}\left(\frac{1}{T}-\frac{1}{T_{r e f}}\right)\right] \\
\cdot\left(x_{i} \gamma_{i} P_{i}^{s a t}-y_{i, Z-S L 1} P_{Z-S L 1}\right) .
\end{gathered}
$$

To our knowledge, this kind of model has not been used to describe the mass transfer in pervaporation through zeolite membranes. In order to predict the fugacity difference across the zeolite film in Eq. (6), the total pressure $P_{Z-S L 1}$ and permeate vapor composition $y_{i, Z-S L 1}$ at the interface between the zeolite film and support layer 1 should be known. The total pressure and composition at the interfaces between the zeolite film and support layer 1, and between support layer 1 and layer 2, cannot be measured directly. Instead, they can be determined on the basis of a mass transfer model for the support.

Surface diffusion preceded by adsorption controls the transport through the zeolite layer, whereas the mode that controls the transport in support is either Knudsen diffusion and/or viscous flow [49]. The component fluxes $\left(\mathrm{mol} \mathrm{m}^{-2} \mathrm{~s}^{-1}\right)$ through support layer 1 (SL1) and support layer 2 (SL2) can thus be written out as a combination of Knudsen diffusion and viscous flow

$$
\begin{aligned}
& J_{S L 1, i}=97 K_{S L 1} \sqrt{\frac{T}{M_{i}}} \frac{\Delta p_{i, S L 1}}{l_{S L 1} R T} \\
& +\left(\frac{B_{0, S L 1}^{e f f}\left(p_{i, Z-S L 1}+p_{i, S L 1-S L 2}\right)}{R T 2 \eta}\right) \frac{\Delta p_{S L 1}}{l_{S L 1}}, \\
& J_{S L 2, i}=97 K_{S L 2} \sqrt{\frac{T}{M_{i}}} \frac{\Delta p_{i, S L 2}}{l_{S L 2} R T} \\
& +\left(\frac{B_{0, S L 2}^{\text {eff }}\left(p_{i, S L 1-S L 2}+p_{i, \text { permeate }}\right)}{R T 2 \eta}\right) \frac{\Delta p_{S L 2}}{l_{S L 2}},
\end{aligned}
$$

where $K(\mathrm{~m})$ is Knudsen structural parameter, $M_{i}\left(\mathrm{~g} \mathrm{~mol}^{-1}\right)$ is the molar mass of component $i, B_{0}^{e f f}\left(\mathrm{~m}^{2}\right)$ is the effective permeability, $\eta$ (Pa s) is the viscosity of the permeate vapor, $l_{S 1}(\mathrm{~m})$ is the thickness of $S L 1$ and $l_{S 2}(\mathrm{~m})$ is the thickness of $S L 2, \Delta p_{i, S L 1}$ and $\Delta p_{i, S L 2}$ are the partial pressure differences across $S L 1$ and $S L 2$ and $\triangle p_{S L 1}$ and $\Delta p_{S L 2}$ are the total pressure differences across $S L 1$ and $S L 2$.

\section{Materials and methods 3.1 Membrane fabrication}

Supported H-ZSM-5 membranes were prepared as described in detail earlier in Hedlund et al. [29]. The thickness of the zeolite film was $0.5 \mu \mathrm{m}$ and the $\mathrm{Si} / \mathrm{Al}$ ratio was 139 [27]. Commercial porous $\alpha$-alumina discs (Fraunhofer IKTS, Germany) comprised of two layers were used as supports. The top layer of $30 \mu \mathrm{m}$ in thickness had $100 \mathrm{~nm}$ pores, and the base layer having a thickness of $3 \mathrm{~mm}$ contained $3 \mu \mathrm{m}$ pores. The discs were first masked [52], then seeded with colloidal silicalite-1 seeds of 50 $\mathrm{nm}$ in size and finally immersed in a synthesis solution for $36 \mathrm{~h}$ at $100^{\circ} \mathrm{C}$. The solution had the molar composition of $3 \mathrm{TPAOH}$ : $25 \mathrm{SiO}_{2}: 1450 \mathrm{H}_{2} \mathrm{O}: 100 \mathrm{C}_{2} \mathrm{H}_{5} \mathrm{OH}$. The synthesized membranes were calcined in air for $6 \mathrm{~h}$ at $500{ }^{\circ} \mathrm{C}$ using a heating rate of $0.2^{\circ} \mathrm{C} \mathrm{min}-1$ and a cooling rate of $0.3^{\circ} \mathrm{C} \mathrm{min}^{-1}$.

\subsection{Pervaporation experiments}

The pervaporation performance of the membranes was studied with binary ethanol/water solutions of 5 / 7.5 / 10 wt.\% ethanol using the pervaporation experimental set-up presented in Fig. 3.

The experiments were carried out at feed temperatures in a range of $30-70{ }^{\circ} \mathrm{C}$. The permeate pressure was kept low with a vacuum pump, varying from $8 \mathrm{mbar}$ at $30^{\circ} \mathrm{C}$ to $24 \mathrm{mbar}$ at $70^{\circ} \mathrm{C}$. After start-up, the membrane was operated close to an hour at each operating temperature in order to attain steady-state conditions. After that, the data was collected. Depending on the flux, the sampling time was 30-60 minutes. 2-3 samples were taken at each experimental temperature for each feed concentration. The samples collected in the liquid nitrogen cold traps were defrosted and weighed. The value for flux $J\left(\mathrm{~kg} \mathrm{~m}^{-2} \mathrm{~h}^{-1}\right)$ was determined by dividing the sample mass by the sampling time and effective membrane area $\left(3.14 \mathrm{~cm}^{2}\right)$.

The composition of samples was analyzed off-line by gas chromatography (Agilent Technologies 6890N Network GC System). The ethanol-water separation factor $\alpha_{E t O H / w a t e r}$ was determined as

$$
\alpha_{E t O H / \text { water }}=\frac{w_{E t O H, p} / w_{\text {water }, p}}{w_{E t O H, f} / w_{\text {water }, f}},
$$


where $w_{E t O H, p}$ and $w_{\text {water }, p}$ are the mass fractions of ethanol and water in the permeate and $w_{E t O H, f}$ and $w_{\text {water, }}$ are the mass fractions of ethanol and water in the feed.

\subsection{Modeling the mass transfer}

The parameters for Models 1-3 were determined by minimizing the sum of squares of the difference between the model and experimental data points, using the optimization routine lsqcurvefit of MATLAB.

The pressure and composition of the vapor mixture at the zeolite-support interface, and thus the driving force for Model 3, was determined on the basis of Eqs. (7) and (8). The structural parameters for the same commercial support as used in the present work are reported in Zhou et al. [28].

The component partial fluxes and permeate partial pressures for Eqs. (7) and (8) were obtained from the experimental data. The partial pressures in Eqs. (7) and (8) at each interface can be replaced with $y_{i} P$, such that the total pressure and composition of the gas mixture at each interface (and thus also the partial pressures) can be determined.

The relative mass transfer resistance over the support is determined as relative mass transfer resistance over the support

$=\frac{p_{i, Z-S L 1}-p_{i, p}}{f_{i, f}-p_{i, p}}$.

The pure component saturated vapor pressures were determined using the Antoine equation (Table 1). The activity coefficients of both the components in the feed mixture and viscosity of the permeate vapor were obtained with a commercial simulation program Aspen Plus, using a Wilson property package.

Table 1 Antoine equation parameters for water and ethanol [53].

\begin{tabular}{ccccc}
\hline Component & A & B & C & Valid [K] \\
\hline water & 5.11564 & 1687.537 & 230.17 & $273.20-473.20$ \\
\hline ethanol & 5.33675 & 1648.220 & 230.918 & $276.50-369.54$ \\
\hline
\end{tabular}

$\log _{10}\left(P_{i}^{\text {sat }}\right)=A-B /(T+C-273.15) . T$ in Kelvin and $P_{i}^{\text {sat }}$ in bar.

\section{Results}

\subsection{Experiments}

Figure 4 shows the total mass flux and separation factor for ethanol-water mixtures as a function of temperature at different feed compositions ( $5 / 7.5$ / 10 wt. $\%$ ethanol). The data points in Fig. 4 are the mean values of the samples with the same experimental conditions. The error bars represent the standard deviation between the replicates. Many of the error bars are smaller than the size of the symbols.

Feed temperature has a significant effect on permeate fluxes due to the strong influence of temperature on fugacity on the liquid side of the membrane. Since the membrane is very thin, the fluxes obtained are high, considerably higher than those

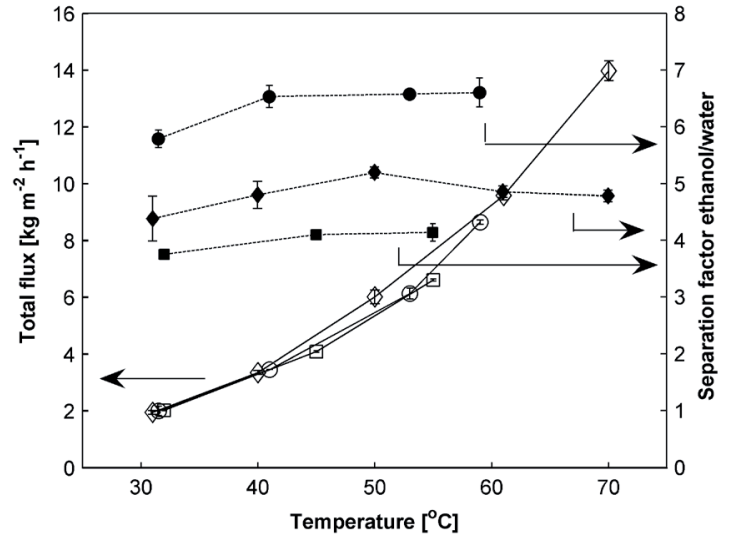

Fig. 4 Total flux (open symbols) and ethanol/water separation factor (filled symbols) as a function of temperature for ethanol/water pervaporation experiments at different feed compositions: (o) 5 wt.\% ethanol, ( $\square$ ) 7.5 wt.\% ethanol, and $(\diamond) 10$ wt. $\%$ ethanol. The lines are guidance for the eye.

previously reported for other MFI membranes with a disc or tubular support. Instead, total flux values on the same level has been reached recently with a hollow fiber MFI membrane [18]. As illustrated in Fig. 4, the temperature dependence of the total flux is both qualitatively and quantitatively the same regardless of the change in the feed composition, as observed also in the study by Weyd et al. [21].

The ethanol/water separation factors observed in the present work are of the same order as typically obtained with polymeric PDMS membranes. In addition, the separation factors are on the same level with the values presented by Korelskiy et al. [26] for a similar high-silica MFI membrane with thin selective zeolite layer. It is worth noting that the membrane investigated in Korelskiy et al. [26] was observed to have a relatively small proportion of defects based on a permporometry study. This implies that the effect of the defects on the selectivity and flux is minor. Nevertheless, the separation factors in this study are lower than in the majority of the ones reported for similar separations with MFI membranes.

The main difference between the high separation factors exhibiting MFI membranes and the membrane investigated in this study is the thickness of the zeolite film as can be seen e.g. in Table 1 in Korelskiy et al. [26]. The MFI membranes with high ethanol/water separation factors typically have a relatively thick zeolite film layer (above $10 \mu \mathrm{m}$ ) and exhibit fluxes below $1 \mathrm{~kg} \mathrm{~m}^{-2} \mathrm{~h}^{-1}$ even at high temperatures, for example Lin et al. [17] had a separation factor of 106 and flux of $0.9 \mathrm{~kg} \mathrm{~m}^{-2} \mathrm{~h}^{-1}$ at $60{ }^{\circ} \mathrm{C}$ with a membrane having a $10-30 \mu \mathrm{m}$ zeolite layer. On the other hand, having a membrane with a thin zeolite layer resulted in high fluxes and low separation factors, for example Algieri et al. [54] obtained a high flux of $2.1 \mathrm{~kg} \mathrm{~m}^{-2} \mathrm{~h}^{-1}$ at $70^{\circ} \mathrm{C}$ but a separation factor of only 1.3 with a membrane having a $2 \mu \mathrm{m}$ zeolite layer. Selectivity and flux are the primary factors determining the practicality of membrane separation. Van der Bruggen and Luis [55] state that a high-performance 
membrane in the case of bioethanol purification is rather a high-flux membrane than a highly selective membrane, which implies that the present work membranes may have potential in bioethanol purification.

The generally observed trade-off between thick and thin membranes and high selectivity and flux, respectively, can be partially attributed to the change of the significance of the support on the mass transport. As reported in Korelskiy et al. [26] the mass transfer resistance of the support may contribute to nearly $80 \%$ of the total resistance with a very thin $0.5 \mu \mathrm{m}$ membrane. Instead, Weyd et al. [21] reported a support pressure drop of $450 \mathrm{~Pa}$, which was approximately $5 \%$ of the total resistance, with a thick $50 \mu \mathrm{m}$ membrane. Thus, the support may have a significant contribution to the mass transfer resistance of the membrane especially when the selective film is thin. Moreover, the description of the support behavior should be included in a membrane mass transfer describing model.

As shown in Fig. 4, the separation factor is the highest for the feed with 5 wt.\% ethanol, and somewhat lower for the feeds with higher ethanol concentrations. The decrease in the ethanol/water separation factor with increasing ethanol concentration in the feed is most probably due to the fact that the adsorption coverage on the feed side, and thus the flux, does not increase in proportion to the feed concentration. There is also a slight temperature-dependency of the separation factor, which is similar for each feed composition: first the selectivity slightly increases as the temperature increases, and then it rather stabilizes as the temperature is further increased. In the study by Chen et al. [19] the pervaporation from ethanol-water mixtures through silicalite-1 membranes shows a similar trend to that observed here.

The apparent activation energy for flux $E_{i}^{a p p}$ (Eq. (1)), which characterizes the overall temperature-dependency of transport in pervaporation, is conventionally determined by plotting $\ln \left(J_{i}\right)$ vs. $1 / T$ [41]. Figure 5 shows that the partial fluxes have an Arrhenius-like dependence on temperature, indicated by the straight lines in the diagram. Thus, the transport in pervaporation is an activated process.

The apparent activation energy for the flux for ethanol and water is determined from the slopes of the individual Arrhenius plots for different feed compositions. As shown in Fig. 5 , the apparent activation energy for the flux for water falls between 41.9-43.1 kJ mol${ }^{-1}$ and for ethanol 45.5-46.8 $\mathrm{kJ} \mathrm{mol}^{-1}$ for feed ethanol compositions varying from 5 to $10 \mathrm{wt} . \%$. The apparent activation energy for the flux is very close to each other for both ethanol and water, but it is slightly larger for ethanol than for water. A higher value of $E_{i}^{a p p}$ implies a more sensitive behavior towards temperature changes, which reflects the slight increase in the ethanol/water separation factor as the temperature is increased.

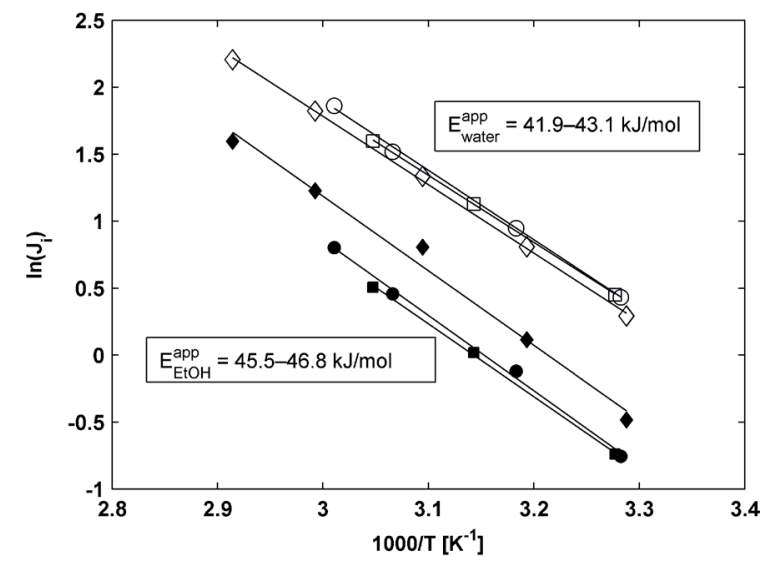

Fig. 5 Arrhenius plots for ethanol (filled symbols) and water (open symbols) for different feed compositions: (o) 5 wt.\% ethanol, () 7.5 wt.\% ethanol, and $(\diamond) 10 \mathrm{wt} . \%$ ethanol.

\subsection{Comparison of Models 1-3}

In each model, the model parameters were fitted to all the experimental data points. The values for the estimated parameters for Models 1-3 are presented in Table 2.

Table 2 Estimated parameters for Models $1-3\left(T_{r e f}=50.5^{\circ} \mathrm{C}\right)$.

\begin{tabular}{ccccc}
\hline & $\begin{array}{c}Q_{E t O H}^{r e f} \\
{\left[\mathrm{~kg} \mathrm{~m}^{-2} \mathrm{~h}^{-1} \mathrm{~Pa}^{-1}\right]}\end{array}$ & $\begin{array}{c}E_{E t O H}^{p} \\
{\left[\mathrm{~kJ} \mathrm{~mol}^{-1}\right]}\end{array}$ & $\begin{array}{c}Q_{\text {water }}^{\text {ref }} \\
{\left[\mathrm{kg} \mathrm{m}^{-2} \mathrm{~h}^{-1} \mathrm{~Pa}^{-1}\right]}\end{array}$ & $\begin{array}{c}E_{\text {water }}^{p} \\
{\left[\mathrm{~kJ} \mathrm{~mol}^{-1}\right]}\end{array}$ \\
\hline Model 1 & $3.97 \times 10^{-4}$ & -1.53 & $3.23 \times 10^{-4}$ & -2.64 \\
\hline Model 2 & $4.18 \times 10^{-4}$ & -2.42 & $3.63 \times 10^{-4}$ & -4.95 \\
\hline Model 3 & $6.28 \times 10^{-4}$ & -5.35 & $7.74 \times 10^{-4}$ & -14.59 \\
\hline
\end{tabular}

The fit of the Models 1-3 to the experimental partial fluxes can be viewed in Figs. 6-8. The experimental data points in Figs. 6-8 are the mean values of the samples from the same experimental conditions, the error bars representing the standard deviation. Many of the error bars are smaller than the size of the symbols.

For Model 3, the relative mass transfer resistance of the support for both ethanol and water determined by Knudsen diffusion and viscous flow with Eqs. (7)-(8) and (10) for different conditions is presented in Table 3 .

The contribution of the support to the mass transfer resistance is substantial for both water and ethanol at all temperatures. Since even more than half of the pressure drop occurs in the support, the reduction of the fugacity difference as driving force limits substantially the component fluxes. The reduced fugacity difference is used as driving force in Model 3. Thus, the derived driving force in Model 3 should be more realistic than in Models 1 and 2.

To be able to compare the models, residuals defined as the difference between the experimentally determined partial flux and the flux predicted by Models 1-3 for both ethanol and 

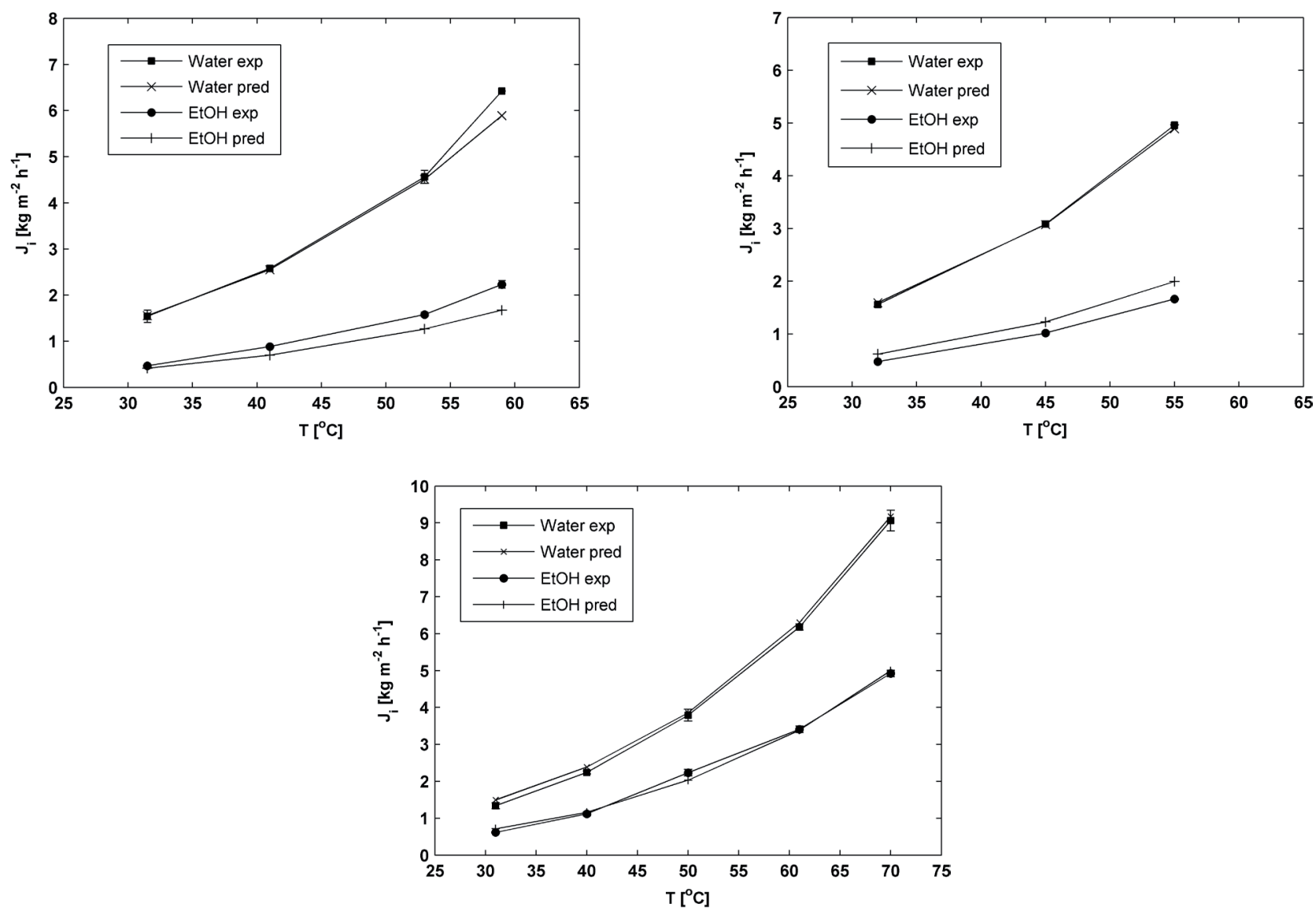

Fig. 6 Experimental and predicted (Model 1) fluxes for ethanol and water for a) 5 wt. $\% \mathrm{EtOH}$, b) $7.5 \mathrm{wt} . \% \mathrm{EtOH}$ and c) $10 \mathrm{wt.} \% \mathrm{EtOH}$ solution as feed. The lines are guidance for the eye.
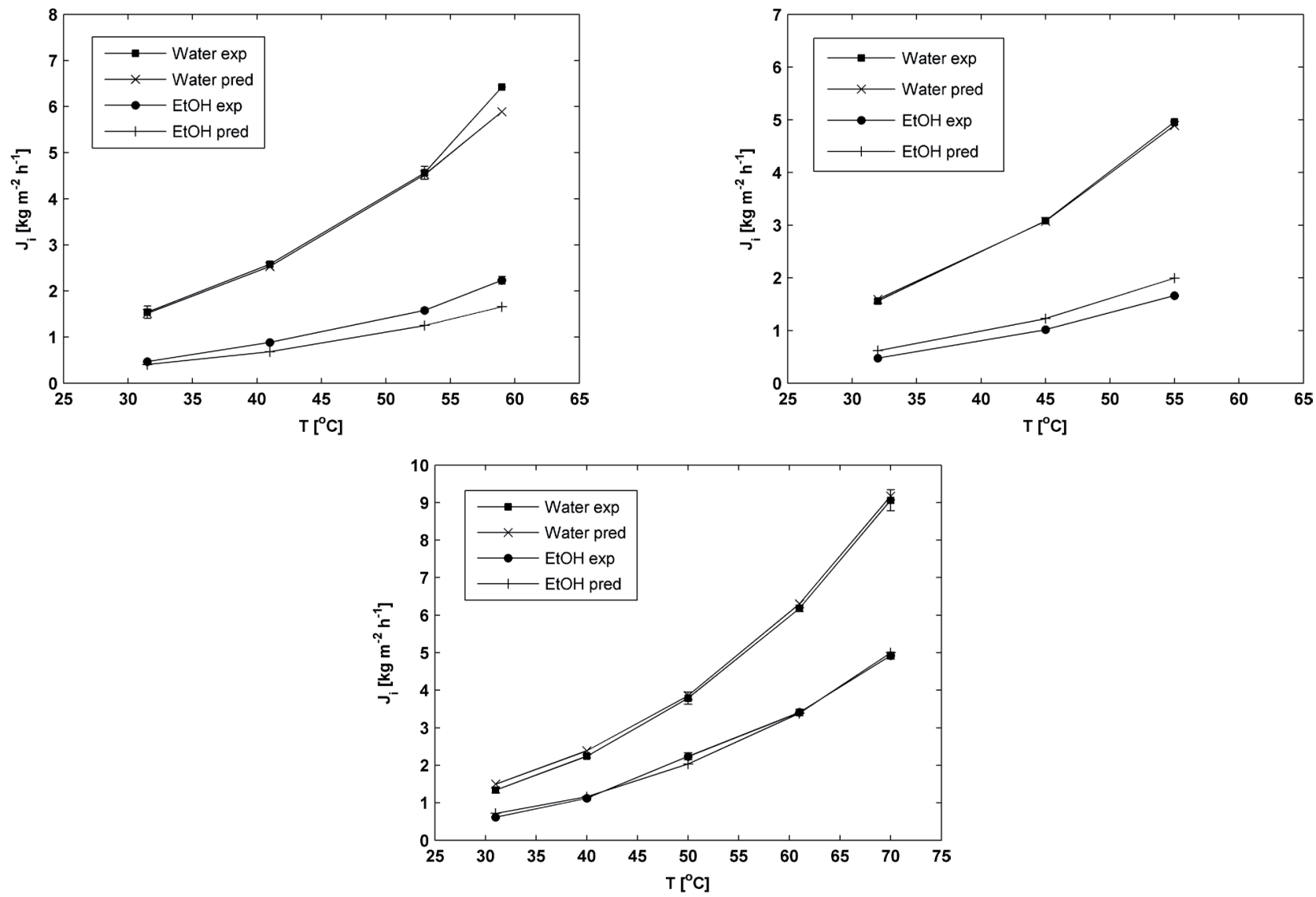

Fig. 7 Experimental and predicted (Model 2) fluxes for ethanol and water for a) $5 \mathrm{wt} . \% \mathrm{EtOH}$, b) $7.5 \mathrm{wt} . \% \mathrm{EtOH}$ and c) $10 \mathrm{wt} . \% \mathrm{EtOH}$ solution as feed. The lines are guidance for the eye. 

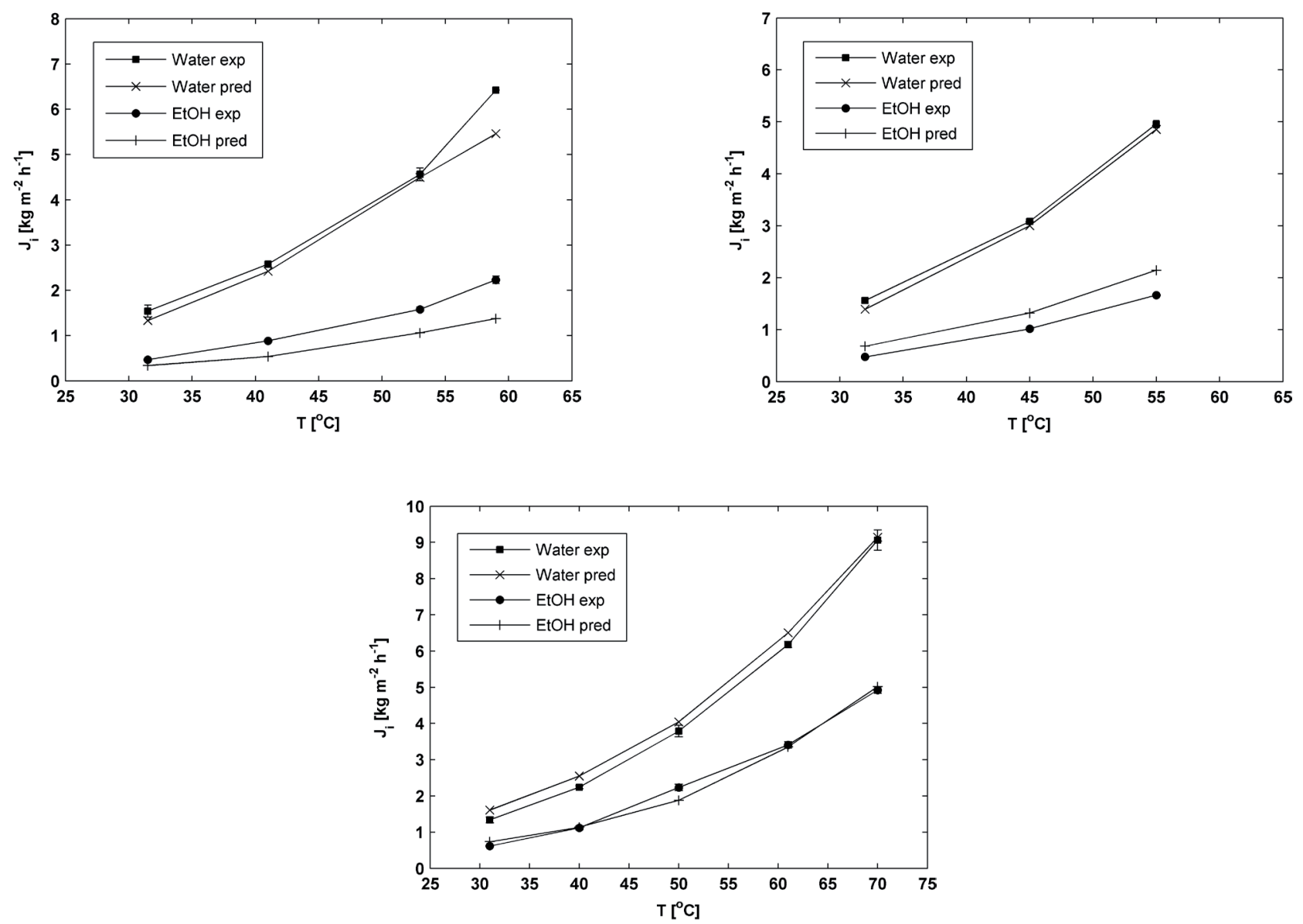

Fig. 8 Experimental and predicted (Model 3) fluxes for ethanol and water for

a) $5 \mathrm{wt} . \% \mathrm{EtOH}$, b) $7.5 \mathrm{wt} . \% \mathrm{EtOH}$ and c) $10 \mathrm{wt} \% \mathrm{EtOH}$ solution as feed. The lines are guidance for the eye.

Table 3 Relative mass transfer resistance of the support for water and ethanol.

$T\left[{ }^{\circ} \mathrm{C}\right]$
$[\%]$

\begin{tabular}{|c|c|c|c|}
\hline \multirow{4}{*}{$\begin{array}{c}\mathrm{EtOH} \\
5 \mathrm{wt} \% \\
\text { feed }\end{array}$} & 31 & 67.0 & 48.2 \\
\hline & 41 & 59.8 & 49.2 \\
\hline & 53 & 52.1 & 43.0 \\
\hline & 59 & 52.4 & 43.1 \\
\hline \multirow{3}{*}{$\begin{array}{c}\text { EtOH } \\
7.5 \text { wt. } \% \\
\text { feed }\end{array}$} & 32 & 65.9 & 31.7 \\
\hline & 45 & 56.8 & 30.1 \\
\hline & 55 & 51.3 & 27.8 \\
\hline \multirow{5}{*}{$\begin{array}{c}\text { EtOH } \\
10 \text { wt.\% } \\
\text { feed }\end{array}$} & 31 & 60.0 & 36.4 \\
\hline & 40 & 55.9 & 37.1 \\
\hline & 50 & 51.5 & 38.3 \\
\hline & 61 & 46.0 & 31.8 \\
\hline & 70 & 42.6 & 28.9 \\
\hline
\end{tabular}



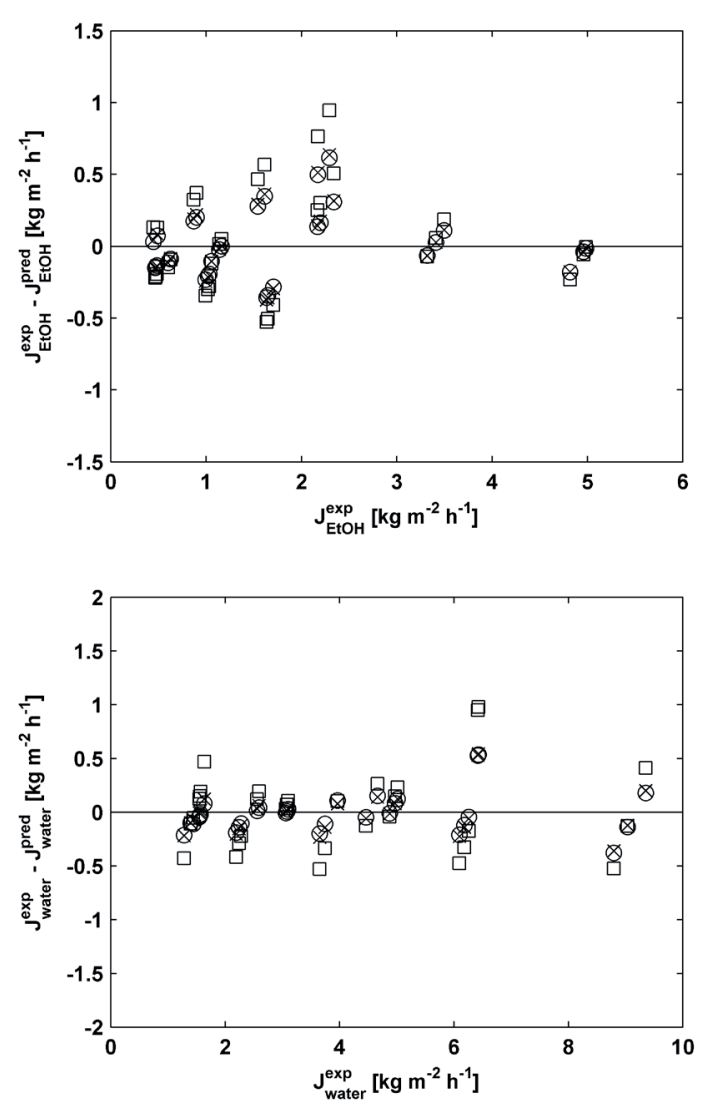

Fig. 9 Residuals for Models $1-3$ as a function of the experimental flux $J_{i}^{\text {exp }}$ for a) Ethanol and b) Water. Model 1 (o), Model 2 (x) and Model 3 (口).

water, are plotted as a function of measured component fluxes, shown in Fig. 9. All the measured partial fluxes are shown in Fig. 9, including the replicates instead of just the mean values.

The average percentage deviation, $\Delta J_{1, i}$, and the degree of dispersion, $\Delta J_{2, i}$, are determined by Eqs. (11) and (12), and presented for both the components in Table 4.

$$
\begin{gathered}
\Delta J_{1, i}=\frac{100}{n} \sum_{j=1}^{n}\left|\frac{J_{i}^{\exp }-J_{i}^{\text {pred }}}{J_{i}^{\exp }}\right| \\
\Delta J_{2, i}=\frac{100}{n} \sum_{j=1}^{n} \frac{\left(J_{i}^{\exp }-J_{i}^{\text {pred }}\right)^{2}}{J_{i}^{\exp }}
\end{gathered}
$$

where $n$ is the number of data points, and $J_{i}^{\text {exp }}$ and $J_{i}^{\text {pred }}$ are the experimental and predicted fluxes of component $i$, respectively.

Table 4 Average percentage deviation $\Delta J_{1, i}$ and degree of dispersion $\Delta J_{2, i}$ for ethanol and water in Models 1-3.

\begin{tabular}{ccccc}
\hline & Average percentage deviation & \multicolumn{2}{c}{ Degree of dispersion } \\
& $\Delta J_{1, \text { EtOH }[\%]}$ & $\Delta J_{1, \text { water }}[\%]$ & $\Delta J_{2, \text { EtOH }}[\%]$ & $\Delta J_{2, \text { water }[\%]}[\%$ \\
\hline Model 1 & 14.5 & 3.7 & 3.5 & 0.8 \\
\hline Model 2 & 15.2 & 3.8 & 3.8 & 0.8 \\
\hline Model 3 & 22.7 & 8.5 & 8.4 & 3.4 \\
\hline
\end{tabular}

As observed from Figs. 6-9 and Table 4, somewhat surprisingly, Model 3 has the least accurate correlation between the fluxes predicted by the model and the experimentally measured fluxes. The correlation is better, and roughly the same with Model 1 and Model 2, where the permeate pressure is either ignored completely, or the experimental bulk permeate values are used. The correlation between the experiments and model prediction is relatively good in each model, especially for water, but for ethanol the deviation is larger.

\section{Discussion}

\subsection{Apparent activation energy for the flux}

In the literature, there are various trends of ethanol/water separation factors with increasing temperature in pervaporation experiments through similar zeolite membranes as studied in this paper. The apparent activation energies for the flux (see Eq. (1)) of water and ethanol (see Fig. 5) are very close to each other ( $\sim 2 \mathrm{~kJ} \mathrm{~mol}^{-1}$ for water and $46 \mathrm{~kJ} \mathrm{~mol}^{-1}$ for ethanol) in this study, as in the study by Chen et al. [19], although they observed slightly smaller apparent activation energies $\left(\sim 30 \mathrm{~kJ} \mathrm{~mol}^{-1}\right)$. Otherwise, the reported apparent activation energies for the flux of water $[16,56,57]$ are similar to those in this study. However, the previously reported apparent activation energies for ethanol with MFI membranes, 32-36 $\mathrm{kJ} \mathrm{mol}^{-1}[16,56,57]$ are smaller than those for water, $41-42 \mathrm{~kJ} \mathrm{~mol}^{-1}[16,56,57]$. In contrast to the present study, Lin et al. [16] and Matsuda et al. [57] reported a decreasing trend of ethanol/water separation factor with increased temperature. The decreasing trend of ethanol/ water separation factor of those studies can be explained by the apparent activation energy for the flux of water being higher than that of ethanol, implying a more sensitive behavior of water towards temperature changes.

\subsection{Activation energy of permeance}

As shown in Table 2, the activation energy of permeance for both ethanol and water is negative. When the activation energy of permeance is negative, the heat of adsorption dominates the generally positive activation energy of diffusion. As a result, with a negative activation energy of permeance, the membrane permeance decreases with increasing temperature. Yet altogether, the flux still increases with increasing temperature because the effect of temperature on saturated vapor pressure, and thus feed side fugacity, is much more significant.

Table 2 shows that the activation energy of permeance for ethanol is less negative than that for water, resulting in the ethanol permeance to decrease less relative to water permeance with increasing temperature. The ratio of the fugacity differences of ethanol and water, on the other hand, is approximately the same for a particular feed composition at different temperatures. Therefore, the impact on the separation factor due to the increase in the component driving force is negligible. Thus, since the activation energy of permeance is less negative for 
ethanol than for water, it is logical that the ethanol/water separation factor slightly increases as the temperature increases.

In a similar separation of ethanol/water mixtures by pervaporation through high-silica MFI membranes, Kuhn et al. [1] reported a more negative activation energy of permeance for ethanol (-10 - -18 $\mathrm{kJ} \mathrm{mol}^{-1}$ for three different membranes), whereas the activation energy of permeance for water was clearly positive (9-21 kJ mol$\left.{ }^{-1}\right)$. The positive activation energy of water permeance indicates that the activation energy of diffusion dominates over the heat of adsorption. Thus, water permeance increases as the temperature increases, being the opposite for ethanol permeance, which partly explains why the separation factor in the study of Kuhn et al. [1] decreases quite substantially, from 40 to 20, as the temperature increases from 75 to $100^{\circ} \mathrm{C}$. It is possible that the membranes studied by Kuhn et al. [1] had a lower Si/Al ratio due to Al leaching from the support layer during the synthesis, making the membrane more polar, compared to the present membranes synthesized by using the support-masking technique.

Generally, as the temperature increases, the diffusion rates increase. In pervaporation through zeolite membranes diffusion favors water permeation because organic molecules in pervaporation are larger than water molecules [13]. Yet, larger molecules generally have larger activation energies of diffusion than small molecules [47]. Thus, the ethanol diffusion coefficient most probably increases more with temperature than water diffusion coefficient leading to that the relative diffusion rate of ethanol is increasing more with increasing temperature compared to the diffusion rate of water.

\subsection{Performance of Models 1-3}

The mass transfer model is feasible when the model correlates with the experimental results, and is also capable of predicting fluxes in conditions other than where the model parameters have been determined. All three models investigated in this paper are based on the semi-empirical mass-transfer model presented in Eq. (2). In this type of model, the driving force is well established, but the membrane properties are grouped together in a permeance term. In other words, Models 1-3 do not require any additional information about the adsorption of components in the zeolite, or the diffusion in the membrane.

As observed from Figs. 6-9, the correlation especially between Models 1 and 2 and experiments is good, but one should use caution when predicting pervaporation performance outside the conditions where the model parameters have been fitted. The advantage of Models 1 and 2 is that they are very easy to apply. These models are sufficient at an early stage of pervaporation modeling, and for the purpose of general process design.

When the driving force is corrected with the contribution of the support (Model 3), the reduction of the driving force is substantial with the very thin membrane studied in this paper (see Table 3). As the driving force is reduced, the role of the permeance $Q$ term becomes more important. Yet, as observed, when the permeance becomes more dominating in Model 3 compared to Models 1 and 2, the correlation between the model and experiments becomes less accurate. This is an indication that the Knudsen diffusion and viscous flow parameters used to model the support mass transfer behavior have some inaccuracy that propagates additional error in the model predictions. Nevertheless, applying the support mass transfer description is expected to yield more detailed information on the behavior of the zeolite film in comparison to the Models 1 and 2. In addition, the applicability of the model outside the experimental domain is improved by using the support mass transfer description.

The effect of temperature on component fluxes, and thus also the separation factor, depends on several factors such as the variation of adsorption of the components in zeolite with temperature, relative changes in the diffusion coefficient for the diffusing species, and also relative changes on the driving force with temperature. In addition, for example the support resistance affects the component fluxes.

The models applied in this paper integrate the effects of adsorption and diffusion solely into a permeance term, without taking into account any variations in adsorption and diffusion as a function of concentration, for example. In order to be able to describe the adsorption and diffusion steps more precisely, detailed information regarding e.g. the material properties and adsorption behavior of the components in the material should be known.

An additional factor that adds to the complexity of pervaporation through zeolite membranes are the non-zeolite pores, i.e. defects. Zeolite membranes are polycrystalline structures consisting of several crystals or grains. While the zeolite pores are defined by the zeolitic crystalline lattice, the non-zeolite pores can be regarded as pathways through the membrane other than the well-defined zeolite pores. Due to the polycrystallinity, it is impossible to eliminate every defect or non-zeolite pore in zeolite membranes [13].

Both the zeolite and non-zeolite pores offer pathways for mass transfer. In non-zeolite pores, the adsorption and diffusion properties of molecules are different in comparison to zeolite pores, which however are difficult to quantify due to the different size and shape of the non-zeolite pores [13]. The hydrophobicity of the high-silica MFI membranes is caused by the Si-O-Si bonds. Therefore, in ethanol/water separation, the hydrophobic zeolite pores favor ethanol instead of water. However, in the case of hydrophobic zeolite membranes, the defects increase the local hydrophilicity due to the terminal silanol (-OH) groups present. Thus, water transport is favored through these pathways due to the hydrophilic nature of dangling $-\mathrm{OH}$ and $\mathrm{O}^{-}$groups [54].

In modeling the mass-transfer in pervaporation, it would be desirable to take adsorption and diffusion into account in a more detailed manner. In addition, the contribution of nonzeolite pores to mass-transfer should be taken into account. Detailed modeling would offer knowledge about the mass 
transfer mechanisms. In addition, high accuracy simulation of specific separations with specific membranes would become possible. This is because generally the parameters in detailed models are more fundamental than in semi-empirical models.

Interaction between the molecules could be taken into account with Maxwell-Stefan modeling. The strength of Maxwell-Stefan modeling is that it comprises intracrystalline diffusion phenomena as well as the adsorption phenomena, and all the parameters applied in the Maxwell-Stefan theory have a physical meaning. So far, modeling the mass-transfer of binary mixtures of organic separations through zeolite membranes using Maxwell-Stefan formulations in pervaporation has not been reported. Thus, in spite of the complexity of the membrane structure and phenomena taking place, detailed modeling of mass transfer is the future direction in modeling pervaporation through zeolite membranes.

\section{Conclusions}

Separation of binary ethanol/water mixtures with ethanol concentration of 5-10 wt.\% through a thin $(500 \mathrm{~nm})$ supported highsilica MFI zeolite membrane by pervaporation at $30-70{ }^{\circ} \mathrm{C}$ was studied. Three mass-transfer models of semi-empirical nature were compared.

Very high total fluxes, as much as $14 \mathrm{~kg} \mathrm{~m}^{-2} \mathrm{~h}^{-1}$ at $70{ }^{\circ} \mathrm{C}$, with separation factors comparable to those reported for polymeric membranes, were observed. Component fluxes were limited by a considerable support resistance as even more than half of the mass transfer resistance was caused by the support.

The correlation between the model and experimental data was best when the driving force for mass transfer was determined over the whole composite membrane from the bulk conditions in the feed and either omitting the permeate fugacity (Model 1) or determining also the permeate fugacity from bulk conditions (Model 2). Besides performing the best, Models 1 and 2 are the easiest to apply. Model 3, where the driving force was determined over the zeolite film after correcting the driving force with the contribution of the support layers, had also good correlation between the model and experiments, but not as good as the other models. The reason for this is likely the inaccuracies in the applied support mass transfer parameters.

Characteristic of empirical or semi-empirical models, the models studied in this paper rely heavily on the experiments. In the context of general process design, the models are primarily suitable for interpolation inside the experimental area.

\section{Acknowledgements}

The postgraduate program Graduate School in Chemical Engineering (GSCE) of Finland is gratefully acknowledged for its financial support. Jonas Hedlund and Danil Korelskiy acknowledge Bio4Energy and the Swedish Foundation for Strategic Research for financial support.

\section{Nomenclature}

\begin{tabular}{|c|c|}
\hline$B_{0}^{e f f}$ & effective permeability $\left(\mathrm{m}^{2}\right)$ \\
\hline$E^{a p p}$ & apparent activation energy for flux $\left(\mathrm{J} \mathrm{mol}^{-1}\right)$ \\
\hline$E^{p}$ & activation energy of permeance $\left(\mathrm{J} \mathrm{mol}^{-1}\right)$ \\
\hline$f$ & fugacity $(\mathrm{Pa})$ \\
\hline$J$ & flux $\left(\mathrm{kg} \mathrm{m}^{-2} \mathrm{~h}^{-1}\right)$ \\
\hline$\Delta J_{1}$ & average percentage deviation $(\%)$ \\
\hline$\Delta J_{2}$ & degree of dispersion $(\%)$ \\
\hline$K$ & Knudsen structural parameter (m) \\
\hline$l$ & thickness of support layer (m) \\
\hline$M$ & molar mass $\left(\mathrm{g} \mathrm{mol}^{-1}\right)$ \\
\hline$P$ & pressure $(\mathrm{Pa})$ \\
\hline$P^{\text {sat }}$ & saturated vapor pressure $(\mathrm{Pa})$ \\
\hline$Q$ & permeance $\left(\mathrm{kg} \mathrm{m}^{-2} \mathrm{~h}^{-1} \mathrm{~Pa}^{-1}\right)$ \\
\hline$R$ & gas constant $\left(8.314 \mathrm{~J} \mathrm{~mol}^{-1} \mathrm{~K}^{-1}\right)$ \\
\hline$T$ & temperature $(\mathrm{K})$ \\
\hline$x$ & mole fraction in liquid phase \\
\hline$y$ & mole fraction in gas phase \\
\hline$w$ & mass fraction \\
\hline
\end{tabular}

\section{Greek letters}

$\begin{array}{ll}\alpha & \text { separation factor } \\ \gamma & \text { activity coefficient } \\ \eta & \text { viscosity (Pa s) }\end{array}$

$\begin{array}{cl}\text { Subscripts } & \\ \text { EtOH } & \text { ethanol } \\ f & \text { feed } \\ i & \text { component } \\ p / \text { perm } & \text { permeate } \\ r e f & \text { reference } \\ \text { SL1 } & \text { support layer 1 } \\ \text { SL2 } & \text { support layer 2 } \\ Z & \text { zeolite film }\end{array}$

\section{Superscripts}

$\begin{array}{ll}\exp & \text { experimental } \\ \text { pred } & \text { predicted }\end{array}$

\section{References}

[1] Kuhn, J., Sutanto, S., Gascon, J., Gross, J., Kapteijn, F. "Performance and stability of multi-channel MFI zeolite membranes detemplated by calcination and ozonication in ethanol/water pervaporation." Journal of Membrane Science. 339 (1-2). pp. 261-274. 2009.

DOI: 10.1016/j.memsci.2009.05.006

[2] Vane, L. M. "A review of pervaporation for product recovery from biomass fermentation processes." Journal of Chemical Technology \& Biotechnology. 80 (6). pp. 603-629. 2005. DOI: 10.1002/jctb.1265

[3] Gaykawad, S. S., Zha, Y., Punt, P. J., van Groenestijn, J. W., van der Wielen, L. A. M., Straathof, A. J. J. "Pervaporation of ethanol from lignocellulosic fermentation broth." Bioresource Technology. 129. pp. 469476. 2013. DOI: 10.1016/j.biortech.2012.11.104 
[4] Rozicka, A., Niemistö, J., Keiski, R. L., Kujawski, W. "Apparent and intrinsic properties of commercial PDMS based membranes in pervaporative removal of acetone, butanol and ethanol from binary aqueous mixtures." Journal of Membrane Science. 453 (0), pp. 108-118. 2014. DOI: 10.1016/j.memsci.2013.10.065

[5] Beaumelle, D., Marin, M., Gibert, H. "Pervaporation with organophilic membranes: State of the art." Transactions of the Institution Chemical Engineering. 71 (C2). pp. 77-89. 1993.

[6] Chen, J., Zhang, H., Wei, P., Zhang, L., Huang, H. "Pervaporation behavior and integrated process for concentrating lignocellulosic ethanol through polydimethylsiloxane (PDMS) membrane." Bioprocess and Biosystems Engineering. 37 (2). pp. 183-191. 2014.

DOI: $10.1007 / \mathrm{s} 00449-013-0984-5$

[7] Chovau, S., Gaykawad, S., Straathof, A. J. J., Van der Bruggen, B. "Influence of fermentation by-products on the purification of ethanol from water using pervaporation." Bioresource Technology. 102 (2). pp. 16691674. 2011. DOI: 10.1016/j.biortech.2010.09.092

[8] Li, L., Xiao, Z., Tan, S., Pu, L., Zhang, Z. "Composite PDMS membrane with high flux for the separation of organics from water by pervaporation." Journal of Membrane Science. 243 (1-2). pp. 177-187.

DOI: 10.1016/j.memsci.2004.06.015. 2004

[9] Chen, X., Ping, Z., Long, Y. "Separation properties of alcohol-water mixture through silicalite-I-filled silicone rubber membranes by pervaporation." Journal of Applied Polymer Science. 67 (4). pp. 629636. 1998. DOI: 10.1002/(SICI)1097-4628(19980124)67:4<629::AIDAPP5>3.0.CO;2-S

[10] Shirazi, Y., Ghadimi, A., Mohammadi, T. "Recovery of alcohols from water using polydimethylsiloxane-silica nanocomposite membranes: Characterization and pervaporation performance." Journal of Applied Polymer Science. 124 (4). pp. 2871-2882. 2012. DOI: 10.1002/app.35313

[11] Vane, L. M., Namboodiri, V. V., Bowen, T. C. "Hydrophobic zeolitesilicone rubber mixed matrix membranes for ethanol-water separation: Effect of zeolite and silicone component selection on pervaporation performance." Journal of Membrane Science. 308 (1-2). pp. 230-241. 2008. DOI: 10.1016/j.memsci.2007.10.003

[12] Peng, P., Shi, B., Lan, Y. "Preparation of PDMS—Silica Nanocomposite Membranes with Silane Coupling for Recovering Ethanol by Pervaporation." Separation Science and Technology. 46 (3). pp. 420-427. 2011. DOI: 10.1080/01496395.2010.527896

[13] Bowen, T. C., Noble, R. D., Falconer, J. L. "Fundamentals and applications of pervaporation through zeolite membranes." Journal of Membrane Science. 245 (1-2). pp. 1-33. 2004. DOI: 10.1016/j.memsci.2004.06.059

[14] Wee, S., Tye, C., Bhatia, S. "Membrane separation process-Pervaporation through zeolite membrane." Separation and Purification Technology. 63 (3). pp. 500-516. 2008. DOI: 10.1016/j.seppur.2008.07.010

[15] Morigami, Y., Kondo, M., Abe, J., Kita, H., Okamoto, K. "The first largescale pervaporation plant using tubular-type module with zeolite $\mathrm{NaA}$ membrane." Separation and Purification Technology. 25(1-3). pp. 251260. 2001. DOI: 10.1016/S1383-5866(01)00109-5

[16] Lin, X., Kita, H., Okamoto, K. "Silicalite Membrane Preparation, Characterization, and Separation Performance." Industrial \& Engineering Chemistry Research. 40(19). pp. 4069-4078. 2001. DOI: 10.1021/ie0101947

[17] Lin, X., Chen, X., Kita, H., Okamoto, K. "Synthesis of silicalite tubular membranes by in situ crystallization." AIChE Journal. 49 (1). pp. 237 247. 2003. DOI: $10.1002 /$ aic.690490122

[18] Shu, X., Wang, X., Kong, Q., Gu, X., Xu, N. "High-Flux MFI Zeolite Membrane Supported on YSZ Hollow Fiber for Separation of Ethanol/ Water." Industrial \& Engineering Chemistry Research. 51 (37). pp. 12073-12080. 2012. DOI: 10.1021/ie301087u
[19] Chen, H., Li, Y., Yang, W. "Preparation of silicalite-1 membrane by solution-filling method and its alcohol extraction properties." Journal of Membrane Science. 296 (1-2). pp. 122-130. 2007.

DOI: 10.1016/j.memsci.2007.03.021

[20] Tuan, V. A., Li, S., Falconer, J. L., Noble, R. D. "Separating organics from water by pervaporation with isomorphously-substituted MFI zeolite membranes." Journal of Membrane Science. 196 (1). pp. 111-123. 2002. DOI: 10.1016/S0376-7388(01)00590-7

[21] Weyd, M., Richter, H., Puhlfürß, P., Voigt, I., Hamel, C., Seidel-Morgenstern, A. "Transport of binary water-ethanol mixtures through a multilayer hydrophobic zeolite membrane." Journal of Membrane Science. 307 (2). pp. 239-248. 2008. DOI: 10.1016/j.memsci.2007.09.032

[22] Sano, T., Hasegawa, M., Ejiri, S., Kawakami, Y., Yanagishita, H. "Improvement of the pervaporation performance of silicalite membranes by modification with a silane coupling reagent." Microporous Materials. 5 (3). pp. 179-184. 1995. DOI: 10.1016/0927-6513(95)00054-D

[23] Negishi, H., Mizuno, R., Yanagishita, H., Kitamoto, D., Ikegami, T., Matsuda, H., Haraya, K., Sano, T. "Preparation of the silicalite membranes using a seeding technique under various hydrothermal conditions." Desalination. 144 (1-3). pp. 47-52. 2002.

DOI: 10.1016/S0011-9164(02)00287-4

[24] Ikegami, T., Yanagishita, H., Kitamoto, D., Negishi, H., Haraya, K., Sano T. "Concentration of fermented ethanol by pervaporation using silicalite membranes coated with silicone rubber." Desalination. 149 (1-3). pp. 49-54. 2002. DOI: 10.1016/S0011-9164(02)00690-2

[25] Zhou, M., Korelskiy, D., Ye, P., Grahn, M., Hedlund, J. "A Uniformly Oriented MFI Membrane for Improved $\mathrm{CO}_{2}$ Separation." Angewandte Chemie International Edition. 53 (13). pp. 3492-3495. 2014. DOI: 10.1002/anie.201311324

[26] Korelskiy, D., Leppäjärvi, T., Zhou, H., Grahn, M., Tanskanen, J., Hedlund, J. "High flux MFI membranes for pervaporation." Journal of Membrane Science. 427. pp. 381-389. 2013.

DOI: $10.1016 /$ j.memsci.2012.10.016

[27] Sandström, L., Lindmark, J., Hedlund, J. "Separation of methanol and ethanol from synthesis gas using MFI membranes." Journal of Membrane Science. 360 (1-2). pp. 265-275. 2010. DOI: 10.1016/j.memsci.2010.05.022

[28] Zhou, H., Korelskiy, D., Leppäjärvi, T., Grahn, M., Tanskanen, J., Hedlund, J. "Ultrathin zeolite X membranes for pervaporation dehydration of ethanol." Journal of Membrane Science. 399-400. pp. 106-111. 2012. DOI: 10.1016/j.memsci.2012.01.036

[29] Hedlund, J., Sterte, J., Anthonis, M., Bons, A., Carstensen, B., Corcoran, N., Cox, D., Deckman, H., De Gijnst, W., de Moor, P., Lai, F., McHenry, J., Mortier, W., Reinoso, J., Peters, J. "High-flux MFI membranes." Microporous and Mesoporous Materials. 52 (3). pp. 179-189. 2002. DOI: 10.1016/S1387-1811(02)00316-5

[30] Fahmy, A. "Membrane processes for the dehydration of organic compounds." PhD Thesis. University of Hannover. 2002.

[31] Bettens, B., Dekeyzer, S., Van der Bruggen, B., Degrève, J., Vandecasteele, C. "Transport of Pure Components in Pervaporation through a Microporous Silica Membrane." The Journal of Physical Chemistry B. 109 (11). pp. 5216-5222. 2005. DOI: 10.1021/jp044515e

[32] Lipnizki, F., Trägårdh, G. "Modelling of pervaporation: Models to analyze and predict the mass transport in pervaporation." Separation \& Purification Reviews. 30 (1). pp. 49-125. 2001. DOI: 10.1081/SPM-100102985

[33] Sommer, S., Melin, T. "Influence of operation parameters on the separation of mixtures by pervaporation and vapor permeation with inorganic membranes. Part 1: Dehydration of solvents." Chemical Engineering Science. 60 (16). pp. 4509-4523. 2005. DOI: 10.1016/j.ces.2005.02.059 
[34] Bettens, B.,Verhoef, A., van Veen, H. M., Vandecasteele, C., Degrève, J., Van der Bruggen, B. "Pervaporation of binary water-alcohol and methanol-alcohol mixtures through microporous methylated silica membranes: Maxwell-Stefan modeling." Computers \& Chemical Engineering. 34 (11), pp. 1775-1788. 2010. DOI: 10.1016/j.compchemeng.2010.03.014

[35] Guo, S., Yu, C., Gu, X., Jin, W., Zhong, J., Chen, C. "Simulation of adsorption, diffusion, and permeability of water and ethanol in $\mathrm{NaA}$ zeolite membranes." Journal of Membrane Science. 376 (1-2), pp. 40-49. 2011. DOI: 10.1016/j.memsci.2011.03.043

[36] Pera-Titus, M., Fité, C., Sebastián, V., Lorente, E., Llorens, J., Cunill, F. "Modeling Pervaporation of Ethanol/Water Mixtures within 'Real' Zeolite NaA Membranes." Industrial \& Engineering Chemistry Research. 47 (9). pp. 3213-3224. 2008. DOI: $10.1021 / \mathrm{ie} 071645 \mathrm{~b}$

[37] Verkerk, A. W., van Male, P., Vorstman, M. A. G., Keurentjes, J. T. F. "Description of dehydration performance of amorphous silica pervaporation membranes." Journal of Membrane Science. 193 (2). pp. 227 238. 2001. DOI: 10.1016/S0376-7388(01)00516-6

[38] Krishna, R., van Baten, J. M. "Investigating the influence of diffusional coupling on mixture permeation across porous membranes." Journal of Membrane Science. 430. pp. 113-128. 2013.

DOI: 10.1016/j.memsci.2012.12.004

[39] Jia, W., Murad, S. "Molecular dynamics simulation of pervaporation in zeolite membranes." Molecular Physics. 104 (19). pp. 3033-3043. 2006. DOI: 10.1080/00268970600946793

[40] Krishna, R., van Baten, J. M. "Highlighting pitfalls in the Maxwell-Stefan modeling of water-alcohol mixture permeation across pervaporation membranes." Journal of Membrane Science. 360 (1-2). pp. 476482. 2010. DOI: 10.1016/j.memsci.2010.05.049

[41] Feng, X., Huang, R. Y. M. "Estimation of activation energy for permeation in pervaporation processes." Journal of Membrane Science. 118 (1). pp. 127-131. 1996. DOI: 10.1016/j.biortech.2012.11.104

[42] Wijmans, J. G., Baker, R. W. "A simple predictive treatment of the permeation process in pervaporation." Journal of Membrane Science 79 (1). pp. 101-113. 1993. DOI: 10.1016/0376-7388(93)85021-N

[43] Rautenbach, R., Herion, C., Meyer-Blumenroth, U. "Engineering aspects of pervaporation: calculation of transport resistances, module optimization and plant design." In: Huang, R. Y. M. (ed.) Pervaporation Membrane Separation Processes. pp. 181-223. Elsevier. Amsterdam. 1991.

[44] Koczka, K., Mizsey, P., Fonyo, Z. "Rigorous modelling and optimization of hybrid separation processes based on pervaporation." Central European Journal of Chemistry. 5 (4). pp. 1124-1147. 2007. DOI: $10.2478 / \mathrm{s} 11532-007-0050-8$

[45] de Bruijn, F., Gross, J., Olujić, Ž., Jansens, P., Kapteijn, F. "On the Driving Force of Methanol Pervaporation through a Microporous Methylated Silica Membrane." Industrial \& Engineering Chemistry Research. 46 (12). pp. 4091-4099. 2007. DOI: 10.1021/ie0610445
[46] Sato, K., Sugimoto, K., Nakane, T. "Preparation of higher flux NaA zeolite membrane on asymmetric porous support and permeation behavior at higher temperatures up to $145{ }^{\circ} \mathrm{C}$ in vapor permeation." Journal of Membrane Science. 307 (2). pp. 181-195. 2008.

DOI: 10.1016/j.memsci.2007.09.017

[47] Bowen, T. C., Li, S., Noble, R. D., Falconer, J. L. "Driving force for pervaporation through zeolite membranes." Journal of Membrane Science. 225 (1-2). pp. 165-176. 2003. DOI: 10.1016/j.memsci.2003.07.016

[48] Nomura, M., Yamaguchi, T., Nakao, S. "Ethanol/water transport through silicalite membranes." Journal of Membrane Science. 144 (1-2). pp. 161 171. 1998. DOI: 10.1016/S0376-7388(98)00043-X

[49] de Bruijn, F. T., Sun, L., Olujić, Ž., Jansens, P. J., Kapteijn, F. "Influence of the support layer on the flux limitation in pervaporation." Journal of Membrane Science. 223 (1-2). pp. 141-156. 2003.

DOI: $10.1016 / \mathrm{S} 0376-7388(03) 00318-1$

[50] Leppäjärvi, T., Malinen, I., Korelskiy, D., Hedlund, J.,Tanskanen, J. "Maxwell-Stefan Modeling of Ethanol and Water Unary Pervaporation through a High-Silica MFI Zeolite Membrane." Industrial \& Engineering Chemistry Research. 53 (1). pp. 323-332. 2014. DOI: 10.1021/ie400814z

[51] Zah, J., Krieg, H. M., Breytenbach, J. C. "Pervaporation and related properties of time-dependent growth layers of zeolite $\mathrm{NaA}$ on structured ceramic supports." Journal of Membrane Science. 284 (1-2). pp. 276-290. 2006. DOI: 10.1016/j.memsci.2006.07.040

[52] Hedlund, J., Jareman, F., Bons, A., Anthonis, M. "A masking technique for high quality MFI membranes." Journal of Membrane Science. 222 (1-2). pp. 163-179. 2003. DOI: 10.1016/S0376-7388(03)00285-0

[53] Poling, B. E., Prausnitz, J. M., O’Connell J. P. "Properties of Gases and Liquids." New York, McGraw-Hill. 2001.

[54] Algieri, C., Bernardo, P., Golemme, G., Barbieri, G., Drioli, E. "Permeation properties of a thin silicalite-1 (MFI) membrane." Journal of Membrane Science. 222 (1-2). pp. 181-190. 2003. DOI: $10.1016 / \mathrm{S} 0376-7388(03) 00286-2$

[55] Van der Bruggen, B., Luis, P. "Pervaporation as a tool in chemical engineering: a new era?." Current Opinion in Chemical Engineering. 4. pp. 47-53. 2014. DOI: 10.1016/j.coche.2014.01.005

[56] Sano, T., Ejiri, S., Yamada, K., Kawakami, Y., Yanagishita, H. "Separation of acetic acid-water mixtures by pervaporation through silicalite membrane." Journal of Membrane Science. 123 (2). pp. 225-233. 1997. DOI: 10.1016/S0376-7388(96)00224-4

[57] Matsuda, H., Yanagishita, H., Negishi, H., Kitamoto, D., Ikegami, T., Haraya, K., Nakane, T., Idemoto, Y., Koura, N., Sano. T. "Improvement of ethanol selectivity of silicalite membrane in pervaporation by silicone rubber coating." Journal of Membrane Science. 210 (2). pp. 433-437. 2002. DOI: 10.1016/S0376-7388(02)00364-2 